\title{
Learning Support for Students with Special Needs at a Public University from the Perspective of Non Academic Staffs
}

\author{
Manisah Mohd Ali, Tarmizi Ahmad, Norshidah Mohamad Salleh, Rosadah Abd Majid \\ Faculty of Education, Universiti Kebangsaan Malaysia, 43600 Bangi, Selangor, Malaysia \\ E-mail:mma@ukm.edu.my
}

\begin{abstract}
Learning support can be defined as support, assistance or services delivered to students with special needs to ensure that they gain full benefit from the teaching and learning process. This research was conducted to look at the learning support received by students with special needs while pursueing their study at a university. This is a case study at a public university in Malaysia. Samples were 6 non academic staffs serving various departments and units at the university. The instrument used to gather the data, was an interview protocol to survey learning support delivered by the non academic staff to students with special needs. The qualitative data was analyzed to describe forms of learning supports delivered to students with special needs. This study found that learning supports provided by the non academic staffs for students with special needs was at average level. The learning support provided include aspects on financial, motivation, career programs, special workshops and demonstrations methods, offering information package, and informing faculties as well as lecturers about the enrolment of students with special needs at the university. This study has implications on the staff professional development programme.
\end{abstract}

Keywords: students with special needs; support; non academic staff;learning; public university

Education empowers one's knowledge, attitudes and potential for success in life. The emphasis on Education for All by the United Nations Educational, Scientific and Cultural Organization see an increasing number of students with special needs attend higher education in the country (UNESCO, 2008). Statistics released by the Malaysian Ministry of Higher Education (2014) show that the number of students with special needs who entered public higher education institution increased from 1, 372 in 2012 to 1,572 students in 2013. This increase is encouraging despite the ongoing issues and challenges such as the understanding and awareness of lecturers and staff on the needs of these. To provide a meaningful and optimal learning experience to students with special needs in higher learning institutions, there should be relevant knowledge, awareness, and support shown by all members of the higher learning institutions including lecturers, support staff and other students. Hadjikakou et al. (2010) explain, internationally, the number of students with special needs entering tertiary institutions is increasing. Research estimates that $8 \%$ to $10 \%$ of these students enrolled in higher education are mostly experiencing learning disabilities. The diverse categories of student with special needs in the university call for different support to be given according to their needs. The widespread participation in higher education has been supported by legal changes, better educational practices and better accessible university programs.

All parties should work together in providing learning support to students with special needs so that they are not left behind in their university learning. The involvement of non-academic staff in the learning for students with special needs is seen as necessary in providing support to these students. Their support extends beyond the academic needs which include infrastructure and social needs. Stumbo et al. (2009) discuss the support that should be addressed by the public universities towards students with special needs who are pursuing further studies at tertiary level. Among the supports listed is personal or individual support by non-academic staff. Such support will provide easier means of understanding and supporting the students. The success of students with special needs is directly influenced by their perceptions of faculty support (Allsopp, Minskoff, \& Bolt, 2005). Thus, this paper discusses the kind of learning support provided by non-academic staff to students with special needs at one of the public universities in Malaysia.

\section{METHOD}

The design of this research is a case study that explores the types of support provided by non-academic staffs to students with special needs. The sample selected consists of non-academic staffs of a public university who have had experience in supporting with students with special needs in the university. The term 'non-academic staffs' refers to staffs of a public university who have experience in providing services other than teaching any academic course. 
Table 1. Samples Description

\begin{tabular}{cll}
\hline Sample & Gender & \multicolumn{1}{c}{ Units } \\
\hline Sample A & Female & Students' Welfare Unit \\
Sample B & Male & Students' Counselling Unit \\
Sample C & Female & Library \\
Sample D & Female & Library \\
Sample E & Female & Academic Management Unit \\
\hline
\end{tabular}

The samples were selected based on their department where they work and their experience in providing support service for students with special needs. A total of six samples which consist of one male and five female samples were selected from various units in the university. Table 1 present the distribution of the selected samples.

An interview protocol with semi-structured items was used in data collection. The interview was carried out in this study because it is an effective method to obtain accurate and honest information on the samples' involvement in providing learning support to students with special needs. The researcher recorded the interview using a voice recorder. After the interview, the researcher extracted the data by coding the responses and transcribed them verbatim. The data were analyzed based on specific emerging themes.

\section{FINDINGS AND DISCUSSION}

Providing learning support from non-academic staffs requires high commitment to ensure that issues and challenges faced during the implementation of learning support could be reduced. This is mentioned by Getzel (2008) who finds that although the number of students with special needs who enroll for academic programmes has increased, the issues and barriers that hinder them from successfully completing their degree programs still exist. The findings of the study reveal three main themes on support based on the interview with the samples. The themes are service support, learning support and socio emotional support.

\section{Service Support}

Something positive gained from this study is that non-academic staffs actually have a sense of responsibility in helping and supporting students with special needs especially in providing learning support to this group of students. Although the number of students with special needs who enrolled in academic programmes at the university is small, they should be given the right and priorities to study and learn along with other typical students. This is emphasized by Zhang et al., (2010) who believed that academic institutions should play their roles in providing fair and equal services to every student. According to sample
A, the welfare unit has provided learning support for students with special needs in terms of financial aid. She described that the unit has helped four students with special needs to receive financial aid from a big agency in the country. This proves the commitment of the welfare unit in playing its roles as the mediator in providing help and support to students with special needs in learning especially from the financial aspect. This is explained by sample A: “..we are always ready to provide help and learning support to students with special needs based on our abilities and authority. For example, in terms of special financial aid, we always send reports on students with special needs to other parties and units to get financial support and so on...".

\section{Learning Support}

Many programmes have been implemented to increase the quality of learning for students with special needs, for instance, through career and motivational programmes. However, one of the samples mentioned that many programmes organized previously specially to boost motivation and self-esteem were not applauded as expected by this group of students. Most of them put more priorities on different matters than spending a little time to get involved in programmes which have been organized such as career programmes. She explained:

“... a variety of programmes have been organized to boost self-motivation among students with special needs especially here in UKM, such as motivational programmes and career programmes. We have invited several people from outside to be the anchors for some motivational and career programmes and most of them who were invited were people with special needs themselves..."

(Sample A)

Sample A also explained that the learning support given to students with special needs include informing the lecturers and faculty if there is any students with special needs enrolling for any academic programmes. This information would assist lecturers in preparing an inclusive learning environment by taking into account students' various backgrounds (Manisah \& Zaleha 2010). Sample A's statement was explained as below:

"...the first help or learning support given to students with special needs is to inform the faculty and the related lecturers about their existence in specific courses. This is important as lecturers are responsible in making sure that students with special needs could enjoy and benefit from the same quality of learning equal to other typical students in lecture halls or tutorials. Lecturers should tailor their instructional strategies in lecture halls to the types of disabilities experienced by their students..." 
Learning support is provided in the context of guidance and teaching. Sample B stated that they will provide teaching and guidance_services to students with special needs so that they are able to attend co curriculum classes as set by the University with positive results. In addition, he also stated that his department will prepare and conduct special programs for the students to enable them to participate in the co curriculum activities,

"... we will teach and guide the students to enable them to perform the activities that are designed for them. We also will recognise the credit hours that are attached to the co curriculum activities performed by them..."

( Sample B)

In addition Sample B reiterated that their unit will:

“...provide services or assistance in accordance with the individual needs of every student with special needs tailored to specific co curriculum activity that they have to undertake..."

In respect of Sample C who works in Library, she stated that support provided to students with special needs are in the form of identifying and providing information to enable them to perform tasks given by their course lecturers. Sample $C$ also stated that learning support in the form of provision of references and digital portal support will further assist the students to complete the course assignments given to them. The forms of support extended will certainly provide these students with more scope and opportunities that enable them to complete their course assignments satisfactorily. As stated by Borklund (2011), these forms of support given to students with special needs will provide them the confidence to manage their learning process on their own without entirely depending on others. Apart from the above, Sample $\mathrm{C}$ indicated that their unit provides additional support at the Library for students with special needs such as special rooms for these students to work on their course assignments and dedicated lifts as well as computers with JAWS programs for students with vision impairment. She stressed:

"...our people in the library focus more on the provision of support or learning aids for students with special needs in relations to the collation of data or information that are required for their course assignments. We assist these students to source for reference material required by them. We will offer them IT support to further facilitate their work assignments. As an example the digital portal offered to them have in its contents, a broad range of information that will assist them in their course work. We have in place in the Library, various forms of support for students with physical disabilities or vision impairment to enable them to have access to reference books and materials placed on racks. These books and other reference material will actually be delivered to these students (when requested by them)..."
Feedbacks received by Sample D stated that learning support extended to students with special needs are already in place but in need of much revamping especially the basic needs of students with special needs in the library such as in the sourcing of reference material and a bigger inventory of books that are designed for use by those students. She further explained that,

“... we are required to prepare sufficient reference material that meets the requirement of the students with special needs, assist them towards sourcing for these material and to have in place adequate special facilities such as ramps and modified tables and chairs..."

\section{Socio Emotional Support}

Support in the form of socio emotional support is the outcome obtained from interviews conducted with Sample E. She stated that their scope of authority centres on the counselling aspect only. Consequently their recommendations within the context of emotional support only cover the aspects of counselling and guidance to students with special needs. Vickerman and Blundell (2010) stress the need for institutions to provide services towards emotional support. Accordingly Sample E clarified the need to create awareness amongst fellow students of students with special needs. It is essential for them to mutually support their course mates in all aspects of the course. This is apparent in her statement as below:

“...we are only permitted to provide counselling and guidance as a means to provide them the essential emotional support in accordance with the charter of the Counselling Unit. We will endeavour to motivate to students with special needs so that their will to continue their studies andl not be hampered by their disabilities. We will create awareness amongst typical students that they have a role to play ... to always provide emotional and physical support to their fellow course mates who are to students with special needs..."

Sample F stated that the Faculty provides learning support in the form of sign language facilitator to students with hearing impairments but only to such students undertaking studies at the Faculty of Education only. Otherwise students with other forms of disabilities are not provided with any other forms of assistance as they are expected to be able to perform with the existing facilities provided by their respective faculties. This situation is clarified by Sample F,

“... for students with hearing impairments, the Faculty will provide a sign language translator to assist them during lectures. Other students with special needs do take the appropriate steps to mitigate their respective challenges..." 


\section{CONCLUSION AND SUGGESTION}

\section{Conclusion}

Based on the research conducted, it is concluded that all the samples demonstrated adequate knowledge and understanding towards students with special needs. Although the level of knowledge is not similar between samples, nevertheless most of them clearly state that they have interacted with students with special needs and have experienced providing learning support to them. It clearly shows that even non-academic staff also extends whatever support they could provide within their respective authorities although such assistance within their respective scope is limited. In addition, all samples agree that it is possible for students with special needs to enter universities for further studies but the facilities provided fall short of the desired level of the individual student with special needs.

\section{Suggestion}

This study revealed that non-academic staff from various departments and units of the University demonstrated a level of open mindedness towards the provision of learning support for students with special needs. Learning support presently provided must recognise the diversity and strength of the individual student with special needs, for example when implementing assessment programs for these students. In the absence of identifiable scope and guiding principles prepared by Universities, this staffs uses their initiatives in extending the learning support to the students. There is a need for workshops and seminars on supporting students with special needs to enable the staff to upgrade the level of professionalism. The nonacademic staffs are fully aware of the responsibility entrusted to them and they are motivated to provide the best services within their respective scope.

\section{Acknowledgement}

This study is part of a research project under the Strategic/ Action Research Grant Scheme of Universiti Kebangsaan Malaysia: PTS-2013-070.

\section{REFERENCES}

Allsopp, D. H., Minskoff, E. H., \& Bolt, L. (2005). Individualized course-specific strategy instruction for college students with learning disabilities and ADHD: Lessons learned from a model demonstration project. Learning Disabilities Practice, 20, 103-118.

Getzel, E. E. (2008) Addressing the persistence and retention of students with disabilities in higher education: Incorporating key strategies and supports on campus. Exceptionality, 16, 207-219.

Hadjikakoua, K., Polycarpoub, V., \& Hadjiliab, (2010). The experiences of students with mobility disabilities in cypriot higher education institutions: Listening to their voices. International Journal of Disability, Development and Education, 57(4), 403-426.

Manisah, M. A., \& Zaleha, S. (2010). Perspectives on readiness and acceptance of lecturers in supporting students with special needs in higher education: A case study. International Conference on Learner Diversity 2010. Procedia Social and Behavioral Sciences 7(C) (2010) 661-664. Retrived 23 October 2017 from http://www.sciencedirect.com/ science/article/pii/S1877042810020938.

Stumbo, N. J., Jay, K., Martin, J. K., Hedrick, B. N., (2009). Personal assistance for students with severe physical disabilities in post-secondary education: Is it the deal breaker? Journal of Vocational Rehabilitation, 30, 11-20.

UNESCO (2008). Konvensyen-konvensyen dan undang-undang yang menjamin hak sama rata semua kanak-kanak untuk kualiti pendidikan di persekitaran yang menyeluruh. Bangkok: UNESCO Bangkok.

Vickerman, P., \& Blundell, M. (2010) Hearing the voices of disabled students in higher education. Disability \& Society, 25(1), 21-32.

Zhang, D., Landmark, L., Reber, A., Yuan, H. H. Oiman, K., \& Benz, M. (2010) University faculty knowledge, beliefs, and practices in providing reasonable accommodations to students with disabilities. Remedial and Special Education, 31(4), 276-286. 